\title{
Asynchronous breathing during sleep
}

\author{
J Kohyama, T Shiiki, M Shimohira, T Hasegawa
}

\begin{abstract}
Background-Children rarely complain of symptoms associated with sleep disordered breathing (SDB). Paradoxical inward rib cage movement (PIRCM) during sleep might prove useful for detecting SDB.

Aims-(1) To determine the correlation between the degree of PIRCM and other measures of disordered breathing during sleep. PIRCM occurs physiologically throughout rapid eye movement sleep in neonates, while no PIRCM has been reported during sleep in adolescents. (2) To determine the chronological changes in the degree of PIRCM.

Methods-PIRCM was quantified by means of the laboured breathing index (LBI). LBI was determined by respiratory inductive plethysmography; PIRCM accompanies a high LBI. Sleep recordings obtained for 101 subjects for various reasons (aged from 3.5 months to 19 years) were analysed.

Results-In 22 records, the minimum $\mathrm{SaO}_{2}$ value was $90 \%$ or more and no obstructive apnoea of more than 10 seconds was observed. In these 22 records, LBI during rapid eye movement sleep decreased significantly with age, reaching the mature low level at 3.3 years of age. In the other 79 records, LBI correlated well with measures of obstructed breathing during sleep. Conclusions-By paying more attention to PIRCM, more obstructed breathing during sleep might be found among children aged 3 years or more.

(Arch Dis Child 2001;84:174-177)
\end{abstract}

Keywords: asynchronous breathing; sleep disordered breathing; obstructive sleep apnoea; laboured breathing index

Sleep disordered breathing (SDB) occurs in about $1-3 \%$ of children. ${ }^{12}$ Children with SDB show more behaviour problems than controls. ${ }^{13}$ However, children rarely complain of symptoms associated with SDB, making diagnosis difficult. Paradoxical inward rib cage movement (PIRCM) or asynchronous breathing occurs in patients with obstructive sleep apnoea or SDB. ${ }^{4}$ We consideered that PIRCM might be useful for detecting SDB.

One of our aims was to determine the correlation between the degree of PIRCM and other measures of disordered breathing during sleep. PIRCM is known to occur physiologically throughout rapid eye movement sleep (REMS) in neonates, ${ }^{5}$ while PIRCM has not been seen during REMS in adolescents. ${ }^{6}$ Although PIRCM during REMS is widely believed to disappear by 3 years of age, ${ }^{4}$ this age dependency has been examined quantitatively only by Gaultier et al. ${ }^{7}$ Our other aim was to determine chronological changes in the degree of PIRCM.

For these purposes, we needed an index to quantify PIRCM. The laboured breathing index (LBI), determined on respiratory inductive plethysmography (RIP), is the sum of the integrals of the absolute values of the derivatives of the inspiratory limbs of the rib cage and abdomen divided by the corresponding integral of the derivative of the inspiratory limb of the tidal volume. ${ }^{8}$ LBI equals 1.0 when the chest and abdominal motions are in perfect synchrony. Any lack of synchrony between them will increase LBI. Qualitative diagnostic calibration performed before each RIP recording allowed us to determine the absolute tidal volume value by RIP. ${ }^{9-11}$ After qualitative diagnostic calibration, LBI has been reported to be stable regardless of a change in body position. ${ }^{89}$ Therefore, we calculated LBI in order to assess PIRCM through all night polysomnography in infants, children, and adolescents.

Unfortunately, as our cohort was not a normal healthy population, we have not obtained normative data. However, the results regarding chronological changes of LBI obtained for subjects without desaturation and obstructive apnoea during sleep corresponded well with previously accepted views on normal subjects (for example, PIRCM during REMS disappears by age 3$){ }^{4}$

\section{Materials and methods}

We analysed 101 all night polysomnographical recordings with complete RIP (RESPISOMNOGRAPH, nims. Inc.) together with percutaneous arterial oxygen saturation $\left(\mathrm{SaO}_{2}\right)$ monitoring obtained between October 1992 and September 1999. All recordings were performed in an isolated semisoundproof recording room with an air conditioner (temperature range, $22-24^{\circ} \mathrm{C}$ ). Each recording included electroencephalography, electro-oculography, electromyography of the chin and trunk muscles, $\mathrm{SaO}_{2}$ monitoring (Ohmeda Biox 3740; averaging time, six seconds), and video monitoring. Oxygen desaturation obtained when the averaging time was set to six seconds on this equipment showed no significant difference from that obtained with the control oximeter. ${ }^{12}$ We did not measure end tidal or transcutaneous carbon dioxide. Sleep stages were determined according to the standard criteria depending on the age at the time of recording. ${ }^{13-15}$

The 101 recordings were obtained for 101 subjects, for various reasons: 57 subjects had respiratory problems during sleep (irregular 
respiration, apnoea, snoring, etc.), 15 had been suggested as having seizures, nine had sleep disturbance (including four with delayed sleep phase syndrome, three with night terrors, and two with hypersomnia), five had group non-A xeroderma pigmentosum, two had breath holding spells, two had Freeman-Sheldon syndrome, and the remaining 11 had other conditions including torsion dystonia, tic, orthostatic dysfunction, anorexia nervosa, hypothyroidism, apparent life threatening event, Angelman syndrome, Duchenne muscular dystrophy, a sibling of a victim of sudden infant death syndrome, a son of a male patient with Joseph disease, and a neurologically unaffected girl with a double cerebral cortex. Their ages ranged from 3.5 months to 19 years (first quartile age, 2.6 years; average age, 6.7 years; third quartile age, 9.6 years; 63 males and 38 females). Informed consent was obtained from all parents and also from the 18 subjects who were older than 12 years, after the procedure and aims had been fully explained.

Five minute qualitative diagnostic calibration was performed before each RIP recording. An episode of apnoea was defined as 10 seconds or more respiratory suppression that did not exceed $25 \%$ of the baseline tidal volume measured during qualitative diagnostic calibration. According to the movements of the chest and abdominal portions during the respiratory suppression, a pause on RIP was determined as obstructive or central..$^{9}$ We did not count central apnoeas following movement according to Marcus et al. ${ }^{16}$

We calculated the average LBI every five minutes. Quality control of the qualitative diagnostic calibration was assessed by means of the quality control factor. ${ }^{17}$ We calculated the average whole night LBI value during nonREMS (LBI-NR) and REMS (LBI-R), respectively. We excluded five minute periods during which changes in the sleep stage (non-REMS and REMS) or massive body movements occurred.

In addition to LBI, we calcuated desaturation time (DT; the percentage of time with $\mathrm{SaO}_{2}$ less than $90 \%$ against the total sleep time), minimum $\mathrm{SaO}_{2}$ level, obstructive apnoea index (incidence of obstructive apnoea per one hour of total sleep time), and central apnoea index (incidence of central apnoea per one hour of total sleep time). We calculated mean $\mathrm{SaO}_{2}$ value separately during both non-REMS and REMS, respectively. The obesity index was also calculated as follows.

body weight - ideal body weight corresponding to height

ideal body weight corresponding to height $\times 100 \%$

The significance of the correlation coefficient $(r)$ between two parameters was assessed by means of the $t$ test. The multiple correlation coefficient $(\mathrm{R})$ was calculated to examine the significance of regression between the age in months and LBI. The significance of regression was assessed by means of $\mathrm{F}$ statistics.

\section{Results}

The minimum $\mathrm{SaO}_{2}$ value in the whole night recordings was observed exclusively during non-REMS in 33 records, during REMS in 56, and during both non-REMS and REMS in the remaining 12. The average minimum $\mathrm{SaO}_{2}$ value in 56 cases who exhibited the minimum $\mathrm{SaO}_{2}$ value during REMS was significantly lower than in the 33 cases who exhibited the minimum $\mathrm{SaO}_{2}$ value during non-REMS $(81.6 \%$ v $87.0 \%, \mathrm{p}<0.05)$. LBI-R was higher than LBI-NR in 74 subjects, equal to LBI-NR in 14, and lower than LBI-NR in the remaining13. Eighteen of the 101 subjects had a central apnoea index exceeding 1.0. However, desaturation below $90 \%$ did not accompany their central sleep apnoea.

We classified the recordings into two types according to the minimum $\mathrm{SaO}_{2}$ value and obstructive apnoea index: 22 without obvious desaturation (minimum $\left.\mathrm{SaO}_{2}>90 \%\right)^{18}$ and obstructive apnoea (obstructive apnoea index $=0)^{19}$; and 79 with desaturation or obstructive apnoea. The maximum change of $\mathrm{SaO}_{2}$ in the 22 records without desaturation and obstructive apnoea was less than $4 \%$.

\section{RECORDS WITHOUT DESATURATION AND} OBSTRUCTIVE APNOEA

Table 1 shows the profiles and sleep variables of the 22 records without desaturation and obstructive apnoea. The correlation between age in months and LBIs was statistically significant for REMS (LBI-R, $r=-0.67$, $\mathrm{p}<0.001$ ), but not significant for non-REMS (LBI-NR, $r=-0.37, \mathrm{p}>0.05)$. The regression curve for the age in months (X) and LBI-R was as follows: $\mathrm{LBI}-\mathrm{R}=1.41 \mathrm{X}^{-0.065} \quad(\mathrm{R}=0.78$, $\mathrm{p}<0.001)$. The upper range (mean $+2.0 \mathrm{SD}$ ) for LBI-R in the 11 subjects aged more than 100 months was 1.11 . The regression curve crossed this value at 39.7 (3.3 years).

\section{RECORDS WITH DESATURATION OR OBSTRUCTIVE} APNOEA

In the other 79 records we calculated correlations between LBIs and the age in months, DT, obstructive apnoea index, minimum $\mathrm{SaO}_{2}$ value, and central apnoea index (table 2 ). The indices other than the age and central apnoea index showed statistically significant correlations with LBIs.

However, some subjects were exceptional. A 13 year old boy (patient A) who complained of nocturnal seizures exhibited no desaturation (minimum $\mathrm{SaO}_{2}>90 \%$ ) and a low obstructive apnoea index (0.3), but showed high LBI values (LBI-NR, 1.42; LBI-R, 2.06). In contrast, an 8 month old boy (patient B) with the complaint of irregular respiration during sleep had a high DT $(8.2 \%)$, a high obstructive apnoea index (7.5), and a low minimum $\mathrm{SaO}_{2}$ value $(69 \%)$, but showed low LBI values (LBINR, 1.04; LBI-R, 1.24).

\section{OBESITY INDEX}

The obesity index ranged from $72.4 \%$ to $-58.0 \%$ with a mean value of 2.0 . The correlation coefficient between the obesity index and 
Table 1 Profiles and sleep parameters of the 22 subjects without desaturation and obstructive apnoea

\begin{tabular}{|c|c|c|c|c|c|c|c|c|}
\hline Age & Sex & Cause of PSG & $\%$ REMS & $\begin{array}{l}\text { Mean } \mathrm{SaO}_{2} \\
\text { non-REMS/REMS }\end{array}$ & $\underset{(\%)}{\operatorname{Min} . \mathrm{SaO}_{2}}$ & $L B I-N R$ & $L B I-R$ & $\begin{array}{l}C A I \\
(/ h)\end{array}$ \\
\hline $3.5 \mathrm{mth}$ & $\mathrm{M}$ & CRS & 39.4 & $98.2 / 97.9$ & 91 & 1.09 & 1.28 & 0.15 \\
\hline $9 \mathrm{mth}$ & $\mathrm{M}$ & CRS & 32.1 & $96.9 / 97.0$ & 92 & 1.08 & 1.30 & 0.48 \\
\hline $9 \mathrm{mth}$ & M & SIDS sibling & 27.5 & $97.5 / 97.4$ & 90 & 1.02 & 1.12 & 0.00 \\
\hline $10 \mathrm{mth}$ & $\mathrm{F}$ & CRS & 23.9 & $97.6 / 97.6$ & 91 & 1.03 & 1.19 & 0.00 \\
\hline 1 y $2 \mathrm{mth}$ & M & CRS & 25.1 & $95.6 / 96.3$ & 91 & 1.15 & 1.18 & 0.00 \\
\hline 1 y $6 \mathrm{mth}$ & M & CRS & 36.8 & $98.3 / 98.1$ & 90 & 1.09 & 1.39 & 0.00 \\
\hline 4 y $2 \mathrm{mth}$ & M & CRS & 23.3 & $97.0 / 97.1$ & 90 & 1.02 & 1.03 & 0.35 \\
\hline $5 \mathrm{y} 11 \mathrm{mth}$ & $\mathrm{F}$ & Epi & 18.9 & $96.3 / 96.9$ & 93 & 1.01 & 1.02 & 0.54 \\
\hline 6 y $7 \mathrm{mth}$ & $\mathrm{F}$ & $\mathrm{XP}$ & 16.4 & $97.8 / 98.5$ & 90 & 1.01 & 1.00 & 0.20 \\
\hline $7 \mathrm{y} 1 \mathrm{mth}$ & $\mathrm{F}$ & Double cortex & 14.1 & $96.9 / 97.0$ & 91 & 1.23 & 1.19 & 0.12 \\
\hline 7 y $2 \mathrm{mth}$ & M & DMD & 16.4 & $96.6 / 96.9$ & 91 & 1.01 & 1.01 & 0.13 \\
\hline 8 y $6 \mathrm{mth}$ & $\mathrm{M}$ & $\mathrm{XP}$ & 17.0 & $95.7 / 96.0$ & 90 & 1.02 & 1.03 & 0.12 \\
\hline 8 y $7 \mathrm{mth}$ & M & CRS & 23.1 & $96.6 / 96.4$ & 91 & 1.00 & 1.00 & 0.00 \\
\hline 9 y 0 mth & $\mathrm{F}$ & $\mathrm{XP}$ & 19.4 & $97.4 / 97.8$ & 94 & 1.01 & 1.01 & 1.11 \\
\hline 9 y $3 \mathrm{mth}$ & $\mathrm{F}$ & AN & 8.5 & $96.4 / 96.3$ & 94 & 1.00 & 1.00 & 0.44 \\
\hline 9 y $3 \mathrm{mth}$ & $\mathrm{F}$ & Epi & 26.5 & $96.5 / 96.7$ & 91 & 1.00 & 1.01 & 0.00 \\
\hline 9 y $5 \mathrm{mth}$ & M & Hypersomnia & 15.3 & $97.5 / 97.5$ & 92 & 1.05 & 1.14 & 0.12 \\
\hline 12 y $11 \mathrm{mth}$ & $\mathrm{F}$ & Epi & 20.0 & $97.1 / 96.7$ & 90 & 1.03 & 1.06 & 0.27 \\
\hline 13 y $5 \mathrm{mth}$ & $\mathrm{F}$ & OD & 21.8 & $96.9 / 97.3$ & 93 & 1.01 & 1.00 & 0.13 \\
\hline 14 y $11 \mathrm{mth}$ & M & DSPS & 16.8 & $97.8 / 97.0$ & 95 & 1.02 & 1.02 & 0.00 \\
\hline 16 y $10 \mathrm{mth}$ & M & Epi & 26.8 & $97.1 / 97.3$ & 91 & 1.03 & 1.01 & 0.75 \\
\hline 19 y $6 \mathrm{mth}$ & $\mathrm{F}$ & Epi & 27.0 & $96.5 / 97.0$ & 93 & 1.01 & 1.01 & 0.86 \\
\hline
\end{tabular}

PSG, polysomnography; \% REMS, percentage of REMS against total sleep time; min. $\mathrm{SaO}_{2}$, minimum SaO ${ }_{2}$ value; CAI, central apnoea index per hour; LBI-NR, laboured breathing index during non-REM sleep; LBI-R, laboured breathing index during REM sleep; CRS, complaining of irregular respiration during sleep; Epi, epilepsy; XP, non-A xeroderma pigmentosum; AN, anorexia nervosa; OD, orthostatic dysfunction; DSPS, delayed sleep phase syndrome.

LBIs calculated for the total 101 recordings was less than 0.1 (not significant).

\section{Discussion}

Obstructive apnoea of more than 10 seconds is not observed in normal subjects aged 3 months or more. ${ }^{19}$ The minimum age of our subjects was 3.5 months. Twenty two of our subjects satisfied this criterion and also exhibited no desaturation (minimum $\mathrm{SaO}_{2}>90 \%$ ), although these 22 subjects did not belong to a healthy population.

In these 22 records (mean $\mathrm{SaO}_{2}$ during REMS ranged from $96.0 \%$ to $98.5 \%$; mean $97.1 \%$, SD $0.6 \%$ ), LBI-R calculated on whole night RIP recording decreased to the mature low level at age 3.3 years. Interestingly, this result was similar to the report of Gaultier et $a l .{ }^{7}$ They assessed PIRCM by visual coding in 13 normal subjects aged from 7 to 31 months (the mean transcutaneous partial pressure of $\mathrm{O}_{2}$ during REMS ranged from 68.7 to 84.8 $\mathrm{mm} \mathrm{Hg}$; mean 76.5; SD 5.5), and concluded that PIRCM in REMS decreased significantly with age. The general notion that PIRCM during REMS disappears by age 3 years ${ }^{4}$ is based on this report. In our study, we found this notion true for subjects without desaturation and obstructive apnoea during sleep, though these subjects were not completely healthy.

REMS atonia is one of the factors that produce PIRCM (that is, elevation of LBI), ${ }^{4-8}$ and facilitate the occurrence of SDB. ${ }^{20}{ }^{21}$ Although the minimum $\mathrm{SaO}_{2}$ value was observed during

Table 2 Correlations between LBI and other indices in the 79 subjects with desaturation or obstructive apnoea

\begin{tabular}{llllll}
\hline & Age & DT & OAI & Min. SaO & CAI \\
\hline LBI-NR & -0.16 & 0.27 & 0.57 & -0.50 & -0.20 \\
p value & $>0.05(\mathrm{~ns})$ & $<0.05$ & $<0.001$ & $<0.001$ & $>0.05$ (ns) \\
LBI-R & -0.03 & 0.32 & 0.65 & -0.57 & -0.22 \\
p value & $>0.05(\mathrm{~ns})$ & $<0.01$ & $<0.001$ & $<0.001$ & $>0.05$ (ns) \\
\hline
\end{tabular}

LBI-NR, laboured breathing index during non-REM sleep; LBI-R, laboured breathing index during REM sleep; OAI, obstructive apnoea index per hour; CAI, central apnoea index per hour; min $\mathrm{SaO}_{2}$, minimum $\mathrm{SaO}_{2}$ value; ns, not significant.
REMS in most of our records, it was also seen during non-REMS. Similarly, LBI-R was higher than LBI-NR in most records, but some exceptional cases were noted. REMS is a state in which desaturation and PIRCM (elevation of LBI) tend to occur. In fact, the average minimum $\mathrm{SaO}_{2}$ value in cases who exhibited the minimum $\mathrm{SaO}_{2}$ value during REMS was significantly lower than in those who exhibited it during non-REMS. However, REMS atonia is not a single determinant of $\mathrm{SDB}^{19}$ or PIRCM (or LBI). The degree of REMS atonia increases with age. ${ }^{22}$ Other factors that overcome this age related development of REMS atonia function to decrease PIRCM with age. As proposed by Gaultier et al, a reduction in chest wall compliance is one of the candidate factors explaining the age related disappearance of PIRCM during REMS. ${ }^{7}$

In contrast to the current results, we found a significant decrease in LBI-NR with age in a larger number of subjects without notable desaturation and obstructive apnoea $(\mathrm{n}=51) \cdot{ }^{23}$ In that preliminary study, we used milder criteria for desaturation and obstructive apnoea than those in the current study. According to these criteria, some young infants who had a high LBI-NR value were included. Studies on factors that affect LBI during nonREMS should also be performed.

Respiratory effort is a factor that could produce PIRCM or increase LBI. To measure respiratory effort, monitoring of oesophageal pressure is the standard method..$^{24}$ However, no absolute level of oesophageal pressure is known to be abnormal. ${ }^{24}$ In contrast to the measurement of oesophageal pressure, PIRCM is easily observed even by caretakers. The correlation between the degree of PIRCM (or the LBI value) and oesophageal pressure as well as the reliability of the caretakers' observation of PIRCM are the next important issues to be examined. Moreover, we have to confirm that PIRCM (elevation of LBI) does not occur even with notable respiratory effort when muscle 
weakness is present. Although these limitations exist, we wondered whether the quantification of PIRCM through LBI could be used to assess the severity of SDB.

In the 79 records with desaturation or obstructive apnoea, we observed statistically significant correlations between LBI and DT, the obstructive apnoea index, and the minimum $\mathrm{SaO}_{2}$ value. However, we found no correlation between LBI and the central apnoea index. We concluded LBI correlated well with measures of obstructed breathing during sleep.

In patient $A$, airflow enough to maintain the $\mathrm{SaO}_{2}$ value might have been maintained by the action of increasing negative intrathoracic pressure against the upper airway obstruction. This negative intrathoracic pressure could produce PIRCM and increase LBI. Unfortunately, a lack of oesophageal pressure data prevented us from diagnosing him as having upper aiway resistance syndrome. ${ }^{25}$ In contrast, patient $\mathrm{B}$ exhibited notable disturbance of the $\mathrm{SaO}_{2}$ value and a high obstructive apnoea index without disturbance of LBI. Mechanisms that cause airway obstruction but do not affect LBI might be involved in this patient.

Obesity is an important factor in causing sleep apnoea in adults, and is also a predisposing factor in children. However, most children with obstructive sleep apnoea are not obese, and abnormal polysomnographical findings were reported to have been obtained in patients who had an obesity index of more than $200 \%{ }^{26}$ Consistently, the correlation between the obesity index and LBI was not significant in our study.

We have shown that LBI correlated with measures of obstructed breathing during sleep. The correlation between the absolute LBI value and the degree of clinically observed PIRCM has not yet been studied, but PIRCM can be easily observed even by caretakers. PIRCM might prove to be a useful tool in detecting obstructed breathing during sleep in children aged 3 or more. By paying more attention to PIRCM, obstructed breathing during sleep might be detected more frequently. PIRCM might also produce a thoracic deformity which could cause cardiorespiratory problems. We should pay more attention to PIRCM.

1 Ali NJ, Pitson DJ, Stradling JR. Snoring, sleep disturbance, and behaviour in 4-5 year olds. Arch Dis Child 1993;68:360-6. 2 Gislason T, Benediktsdóttir B. Snoring, apneic episodes, and nocturnal hypoxemia among

3 Ali NJ, Pitson DJ, Stradling JR. Natural history of snoring and related behaviour problems between the ages of 4 and 7 years. Arch Dis Child 1994;71:74-6.

4 Rosen CL. Obstructive sleep apnea syndrome (OSAS) in children: diagnostic challenges. Sleep 1996;19:S274-7.

5 Curzi-Dascalova L. Thoraco-abdominal respiratory correlations in infants: constancy and variability in different sleep states. Early Hum Dev 1978;58:25-38.

6 Tabachnik E, Muller NL, Bryan AC, et al. Changes in ventilation and chest wall mechanics in normal sleeping adolescents. $\mathcal{F}$ Appl Physiol 1981;51:557-64.

7 Gaultier C, Praud JP, Canet E, et al. Paradoxical inward rib cage motion during rapid eye movement sleep in infants and young children. F Dev Physiol 1987;9:391-7.

8 Warren RH, Horan SM, Robertson PK. Chest wall motion n preterm infants using respiratory inductive plethysmography. Eur Respir f 1997;10:2295-300.

9 Krieger BP. Respiratory inductive plethysmography. Probl Respir Care 1989;2:156-75.

10 Chadha TS, Watson H, Birch S, et al. Validation of respiratory inductive plethysmography using different calibration procedures. Am Rev Respir Dis 1982;125:644-9.

11 Sackner MA, Watson H, Belsito AS, et al. Calibration of respiratory inductive plethysmograph during natural breathpiratory inductive plethysmograph
ing. $\mathcal{F}$ Appl Physiol 1989;66:410-20.

12 Farré R, Monteserrat JM, Ballester E, et al. Importance of the pulse oximeter averageing time when measuring oxygen desaturation in sleep apnea. Sleep 1998;21:386-90.

13 Anders T, Emde R, Parmelee A. A manual of standardized terminology, techniques and criteria for scoring of states of sleep and wakefulness in newborn infants. Los Angeles: UCLA Brain Information Service/BRI Publications Office, 1971.

14 Guilleminault C, Souquet M. Sleep states and related pathology. In: Korobkin R, Guilleminault C, eds. Advances in perinatal neurology. New York: Spectrum Publications, 1979:225-47.

15 Rechtschaffen A, Kales A. A manual of standardized terminology, techniques and scoring system for sleep stages of human subjects. Washington DC: US Government Printing Office, 1968 .

16 Marcus CL, Omlin KJ, Basinki DJ, et al. Normal polygraphic values for children and adolescents. Am Rev Respir Dis 1992;146:1235-9.

7 Sackner MA. Non-invasive respiratory monitoring. NonInvasive Monitoring Systems, Inc., 1986.

18 Brouillette RT, Weese-Mayer DE, Hunt CE. Disorders of breathing during sleep in the pediatric population. Semin Respir Med 1988;9:594-606.

19 Carroll JL, Loughlin GM. Obstructive sleep apnea syndrome in infants and children: diagnosis and management. In: Ferber R, Kryger M, eds. Principles and practice of sleep medicine in the child. Philadelphia: WB Saunders, 1995: 193-216.

20 Issa FG, Sullivan CE. Upper airway closing pressures in obstructive sleep apnea. F Appl Physiol 1984;57:520-7.

21 Kohyama J, Shimohira M, Hasegawa T, et al. Phasic motor activity reduction occurring with horizontal rapid eye movements during active sleep in human. Exp Brain Res 1995;107:137-44.

22 Kohyama J, Tachibana N, Taniguchi M. Development of REM sleep atonia. Acta Scand Neurol 1999;99:368-73.

23 Kohyama J, Shiiki T, Sakuma H, Shimohira M, Hasegawa T. Age-related changes of paradoxical inward rib cage movement during sleep. Sleep Res Online 1999;2(suppl 1): 112 .

24 American Academy of Sleep Medicine Task Force. Sleeprelated breathing disorders in adults: recommendation for syndrome definition and measurement techniques in clinical research. Sleep 1999;22:667-89.

25 Guilleminault C, Pelayo R, Leger D, et al. Recognition of sleep-disordered breathing in children. Pediatrics 1996;98: sleep-disor $871-82$.

26 Carroll JL, Loughlin GM. Obstructive sleep apnea syndrome in infants and children: clinical features and pathophysiology. In: Ferber R, Kryger M, eds. Principles and practice of sleep medicine in the child. Philadelphia: WB Saunders, 1995:163-91. 